\title{
Study on Sodium Modification of Inferior Ca-Based Bentonite by Suspension Method
}

\author{
Yuanbo Zhang, Tao Jiang, Liyong Chen, and Guanghui Li \\ School of Minerals Processing \& Bioengineering, Central South University, Changsha 410083, China \\ Correspondence should be addressed to Tao Jiang, jiangtao@csu.edu.cn \\ Received 21 April 2011; Accepted 5 June 2011 \\ Academic Editor: C. Subramanian
}

Copyright () 2011 Yuanbo Zhang et al. This is an open access article distributed under the Creative Commons Attribution License, which permits unrestricted use, distribution, and reproduction in any medium, provided the original work is properly cited.

Hunyuan Ca-based bentonite is one of large-type bentonite deposits in China, the reserve of which is more than 0.15 billion tons. However, they are not completely utilized in the pellet production. Process mineralogy investigation shows that the bentonite is a kind of typical Ca-bentonite (Ca-Bent). The sodium modification of the sample is studied by suspension method in this study. Results present the alkali coefficient $K$ of modified Na-bentonite that is increased from 0.34 to 1.33 , and the $2 \mathrm{HWA}$, dilation, and colloid index are, respectively, increased to $601 \%, 32.4 \mathrm{~mL} / \mathrm{g}$ and $87.6 \mathrm{~mL} /(3 \mathrm{~g})$ under optimal conditions of $\mathrm{Na}_{2} \mathrm{CO}_{3} \mathrm{dosage}_{3.0} \%$, pulp density $20 \%$, sodium temperature $55^{\circ} \mathrm{C}$, and sodium time $0.5 \mathrm{~h}$. The XRD patterns show that $d(001)$ of the sample bentonite is reduced from $1.5539 \mathrm{~nm}$ down to $1.2467 \mathrm{~nm}$, and $2 \theta(001)$ of the sample bentonite is increased from $5.6875^{\circ}$ to $7.0907^{\circ}$, indicating that the sample Ca-Bent is effectively modified into Na-Bent.

\section{Introduction}

Being high dispersity, hydrophilic property, and viscosity, bentonite is widely used in the pellet production to improve the strength of green and dry pellets as well as the bursting temperature of green pellets [1-5]. In commercial production, bentonite quality has obvious effects on the production cost and the quality of products. The practice has shown that about $90 \%$ of bentonite is residual in the finished pellets, reducing total iron ( $\mathrm{TFe}$ ) grade of roasted pellets. For blast furnaces, the coke rate is lowered by $2 \%$, and output is increased by $3 \%$ if TFe grade of charging is enhanced by $1 \%$. Thus, improving the bentonite quality has great importance to the iron and steel industry.

Presently, average dosage of bentonite, most of them are Ca-Bent, is between $2.5 \%$ and $4 \%$ in domestic pellet plants. Generally speaking, the balling effect using Na-Bent is better than that using Ca-Bent if the dosage is equal [6]. Therefore, in order to reduce the bentonite dosage, it is necessary to modify the inferior Ca-Bent into superior Na-Bent.

Hunyuan bentonite is one of large-type bentonite deposits in China, the reserve of which is more than 0.15 billion tons. It is a typical kind of Ca-Bent, and the dosage of it is high to $3.0 \% \sim 3.5 \%$ when used as pellet binder. So, they should be firstly subjected to sodium modification so as to be widely used in pellet production. Three methods are usually used to sodium modification $[7,8]$ : suspension method, semidry process, and screw extrusion method. Comparatively, suspension method makes the sodium reaction happen in solution, and the time for this method is the shortest.

In this investigation, based on the physicochemical properties and process mineralogy of the Ca-Bent, effects of different factors on the sodium modification by means of suspension method are studied, which provides an effective route for the utilization of Hunyuan Ca-Bent.

\section{Materials}

The main chemical compositions of the sample bentonite are shown in Table 1. According to the formula $K=\left(E_{\mathrm{Na}^{+}}+\right.$ $\left.E_{\mathrm{K}^{+}}\right) /\left(E_{\mathrm{Ca}^{2+}}+E_{\mathrm{Mg}^{2+}}\right)$, the alkali coefficient $K$ is $0.34(<1)$, indicating that this bentonite is a typical Ca-Bent [1].

The chemical phases of silicon in the Ca-Bent show that $94.08 \% \mathrm{SiO}_{2}$ exists in silicates, and $5.92 \% \mathrm{SiO}_{2}$ exists as the dissociated form. As far as calcium is concerned, $78.06 \%$ of $\mathrm{CaO}$ exists in Ca-montmorillonite, and $12.66 \%$ of $\mathrm{CaO}$ is in the insoluble silicates. 
TABle 1: Chemical compositions of the sample Ca-Bent (wt.\%).

\begin{tabular}{cccccccccc}
\hline $\mathrm{SiO}_{2}$ & $\mathrm{Al}_{2} \mathrm{O}_{3}$ & $\mathrm{Fe}_{2} \mathrm{O}_{3}$ & $\mathrm{CaO}$ & $\mathrm{MgO}$ & $\mathrm{K}_{2} \mathrm{O}$ & $\mathrm{Na}_{2} \mathrm{O}$ & $\mathrm{P}$ & $\mathrm{S}$ & LOI* $^{*}$ \\
\hline 66.73 & 14.05 & 1.86 & 2.37 & 1.20 & 1.06 & 0.84 & 0.010 & 0.015 & 9.79
\end{tabular}

${ }^{*}$ Note: LOI is loss of ignition.

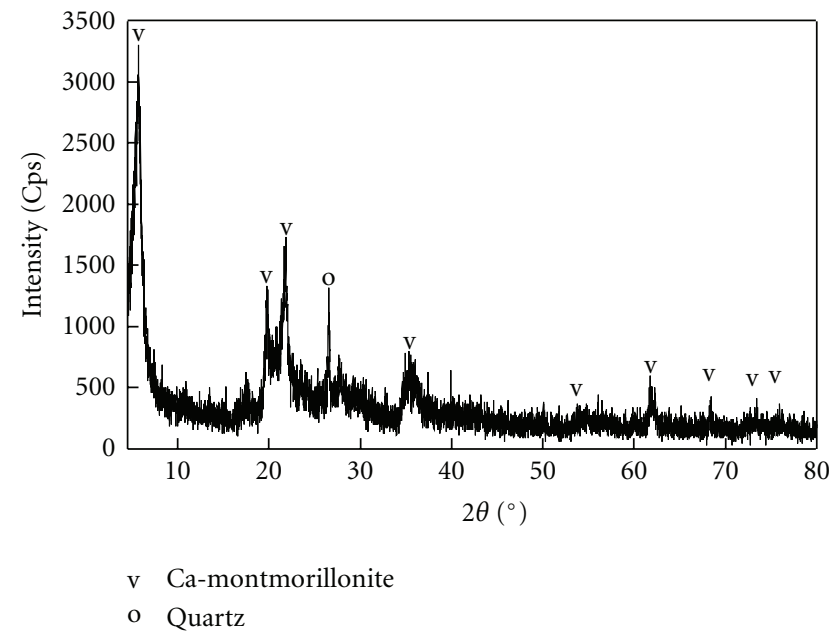

FIgURE 1: XRD pattern of Hunyuan Ca-Bent.

It can be seen from Figure 1 that $\mathrm{Ca}$-montmorillonite is the leading minerals in the bentonite apart from a small quantity of dissociated quartz. Figure 2 shows the flaky and plate-like particles of Ca-montmorillonite and Figure 3 presents the dissociated quartz enwrapped by the montmorillonite.

The basic physical indexes of the sample as pellet binders are presented in Table 2 .

All the sodium agents, including $\mathrm{NaF}, \mathrm{Na}_{2} \mathrm{CO}_{3}, \mathrm{NaOH}$, $\mathrm{Na}_{3} \mathrm{PO}_{4}$, and $\mathrm{NaCl}$, are chemical pure.

\section{Experimental Methods}

The experimental procedures are described as follows: to begin with, the Ca-Bent is ground, of which the granularity below $0.1 \mathrm{~mm}$ accounts for $90 \%$. $100 \mathrm{~mL}$ of distilled water is put into a $200 \mathrm{~mL}$ beaker. After that, a certain quality of dried Ca-Bent and sodium salt is added into the same beaker and stirred for $3 \mathrm{~min}$ in order to disperse the materials evenly, and, then, the beaker is laid in a homothermal water-bath and heated at a given temperature for a certain time. In the bentonite-water system, there exist plenty of $\mathrm{Ca}^{2+}$ and $\mathrm{Na}^{+}$, the following reaction will occur:

$$
\mathrm{Ca}-\mathrm{Bent}+2 \mathrm{Na}^{+}=2 \mathrm{Na}-\mathrm{Bent}+\mathrm{Ca}^{2+} \text {. }
$$

After the sodium modification is finished, the slurry is filtered, then the filter residues are dried at $95 \pm 5^{\circ} \mathrm{C}$ for more than 6 hours. Finally, the dried bentonite is ground to the granularity of $99 \%$ below $0.075 \mathrm{~mm}$.

Literatures indicate $[7,8]$ that the $2 \mathrm{HWA}$ and the dilation of Na-Bent are better than those of Ca-Bent, because $\mathrm{Na}$ montmorillonite can be dispersed into single crystal while

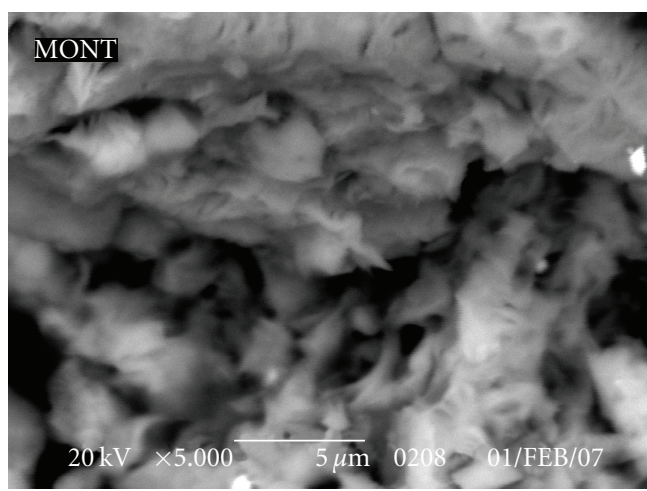

FIGURE 2: SEM image of Ca-montmorillonite.

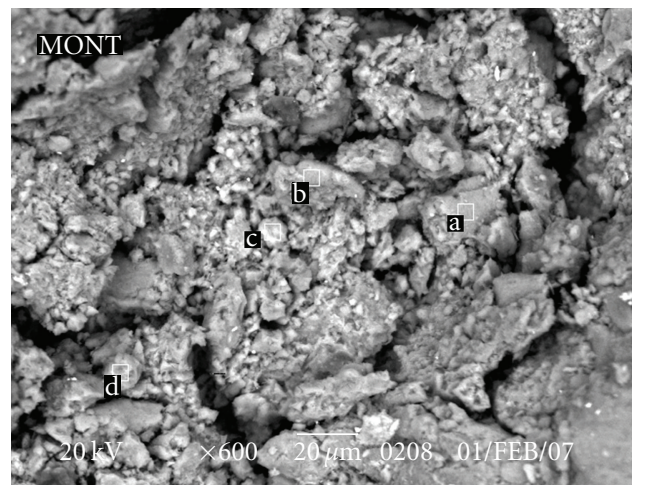

FIGURE 3: SEM image of quartz enwrapped by Ca-montmorillonite (a, b, d-quartz, and c-montmorillonite).

TABLE 2: Basic physical properties of the sample Ca-Bent.

\begin{tabular}{lccc}
\hline Ca-montmorillonite (\%) & $\begin{array}{c}2 \mathrm{HWA}^{*} \\
(\%)\end{array}$ & $\begin{array}{c}\text { Dilation } \\
\left(\mathrm{mL} \cdot \mathrm{g}^{-1}\right)\end{array}$ & $\begin{array}{c}\text { Colloid index } \\
\left(\mathrm{mL} \cdot(3 \mathrm{~g})^{-1}\right)\end{array}$ \\
\hline 86.0 & 195 & 8.3 & 19.0 \\
\hline
\end{tabular}

* Note: 2 HWA refers to water absorbtion content in 2 hours.

Ca-montmorillonite can be only dispersed into the polymer composed of tens of single crystals. So, 2HWA and dilation are often used to evaluate the sodium-modification effect in these investigations, and so is in this research.

$\mathrm{XRD}$ is applied to distinguish Ca-Bent from Na-Bent. Literatures $[7,9,10]$ reveal that the montmorillonite has the strongest intensities and bright peaks on (001) crystal face. Moreover, $d(001)$ of Ca-Bent is about $1.55 \mathrm{~nm}$, and $2 \theta(001)$ is $5.66^{\circ}$; relatively, $d(001)$ of $\mathrm{Na}-\mathrm{Bent}$ is $1.25 \mathrm{~nm}$, and $2 \theta(001)$ is $7.1^{\circ}$.

\section{Results and Discussion}

4.1. Factors Affecting Sodium Modification. Many factors have obvious effects on the sodium modification of Ca-Bent. In this paper, the following primary parameters, including category and dosage of sodium agent, sodium temperature and time and pulp density, are investigated. 


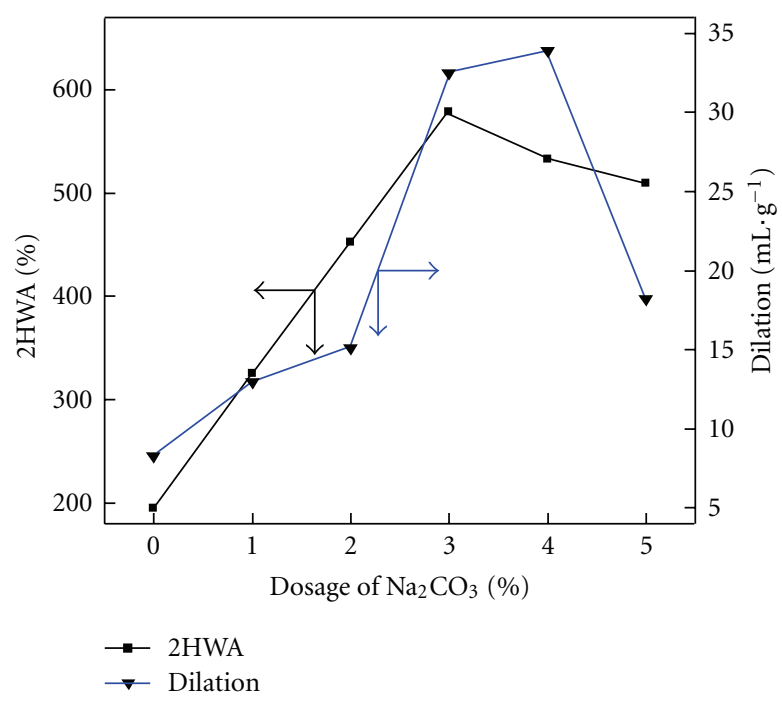

FIgURE 4: Effects of $\mathrm{Na}_{2} \mathrm{CO}_{3}$ dosage on sodium modification.

4.1.1. Dosage of $\mathrm{Na}_{2} \mathrm{CO}_{3}$. To start with, effects of $\mathrm{Na}_{2} \mathrm{CO}_{3}$ dosage on the 2HWA and dilation of modified bentonite are studied, fixing the conditions of pulp density $20 \%$, sodium temperature $25^{\circ} \mathrm{C}$, and sodium time $0.5 \mathrm{~h}$, and the final results are plotted in Figure 4.

Seen from Figure 4, 2HWA and dilation of the unmodified Ca-Bent are far less than those of modified Na-Bent. With ascending of $\mathrm{Na}_{2} \mathrm{CO}_{3}$ dosage, 2HWA and dilation have the similar changing rule of first increase and then decrease, which reaches the maximum at the dosage of $3.0 \%$ and $4.0 \%$, respectively. Studies mentioned above have shown that $1.85 \% \mathrm{CaO}$ is contained in the Ca-montmorillonite. Supposing that $\mathrm{Ca}^{2+}$ can be completely replaced with $\mathrm{Na}^{+}$, theoretic dosage of $\mathrm{Na}_{2} \mathrm{CO}_{3}$ is calculated as $3.5 \%$ according to reaction (1) mentioned before, which is almost equivalent to the actual dosage used. When $\mathrm{Na}_{2} \mathrm{CO}_{3}$ dosage is below the suitable quantity, $\mathrm{Na}^{+}$content in the liquid is evidently increased if the $\mathrm{Na}_{2} \mathrm{CO}_{3}$ dosage is heightened, which improves the reaction probability between $\mathrm{Na}^{+}$and $\mathrm{Ca}^{2+}$. After the $\mathrm{Na}_{2} \mathrm{CO}_{3}$ dosage exceeds the right value, the excessive free $\mathrm{Na}^{+}$exists in the solution, and partial $\mathrm{Na}^{+}$ ions are absorbed to the surface of the montmorillonite crystal grains to form a hydrated shell, preventing the outer moisture from entering between the crystal layers. Moreover, the balance of ion-exchange reaction between $\mathrm{Na}^{+}$and $\mathrm{Ca}^{2+}$ is destroyed owing to free $\mathrm{Na}^{+}$having high ionization rate and activity. The interlamellar spacing between crystal grains is compressed, so part of the interlayer water is extruded out, which is adverse to the sodium reaction [11].

From the results obtained, the suitable $\mathrm{Na}_{2} \mathrm{CO}_{3}$ dosage is $3.0 \% \sim 3.5 \%$.

4.1.2. Pulp Density. Effects of pulp density on the sodiummodification are performed when $\mathrm{Na}_{2} \mathrm{CO}_{3}$ dosage is $3.0 \%$, sodium temperature is $25^{\circ} \mathrm{C}$, and sodium time is $0.5 \mathrm{~h}$, and the variation curves of $2 \mathrm{HWA}$ and dilation of modified bentonite are shown in Figure 5.

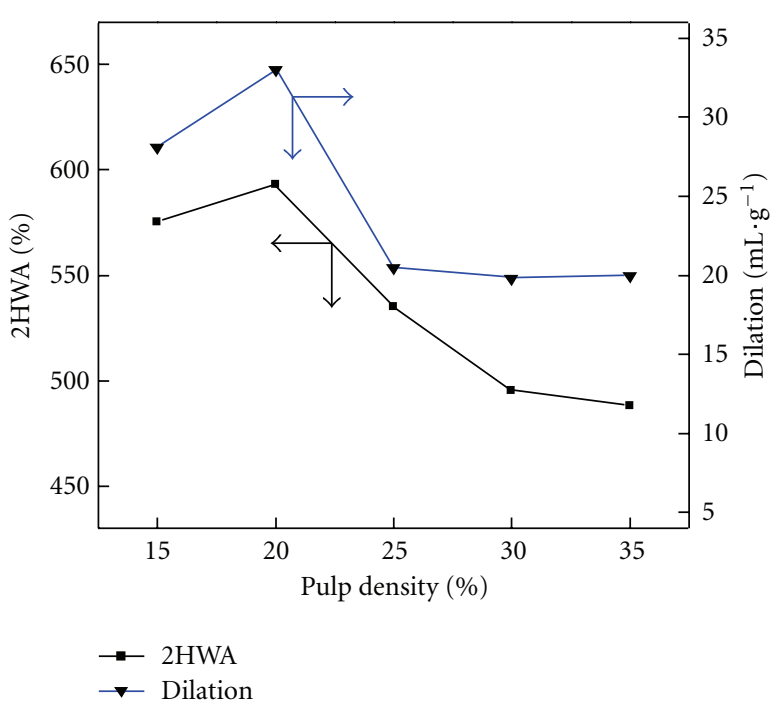

FIgURE 5: Effects of pulp density on sodium modification.

Figure 5 indicates that the 2HWA and dilation are relatively the best when pulp density is $20 \%$, being $593 \%$ and $33.0 \mathrm{~mL} / \mathrm{g}$, respectively. With the rising of pulp density, the content of $\mathrm{Na}^{+}$and $\mathrm{Ca}^{2+}$ in solution is improved, increasing the probability of ion exchange between $\mathrm{Na}^{+}$and $\mathrm{Ca}^{2+}$. While the pulp density is in excess of $20 \%$, the montmorillonite crystal grains cannot be dispersed adequately due to the apparent increase of solution viscosity, resulting in the diffusion velocity of $\mathrm{Na}^{+}$decreased to a certain extent. In addition, electrical double layers of montmorillonite mutually repulse and are suppressed $[12,13]$, which hinder the sodium reaction. Thus, the effect of sodium modification becomes worse.

4.1.3. Sodium Temperature. Figure 6 is the changing curves of sodium temperature affecting the 2HWA and dilation of the modified bentonite. The other parameters are fixed as the following: $3.0 \% \mathrm{Na}_{2} \mathrm{CO}_{3}$ dosage, $20 \%$ pulp density, and $0.5 \mathrm{~h}$ sodium time.

As shown in Figure 6, sodium temperature also has perceivable impact on the 2HWA and dilation. Comparatively speaking, the effect of sodium modification is the best when the sodium temperature is $55^{\circ} \mathrm{C}$. In the double electric layer of bentonite-water system, $\mathrm{Na}^{+}$in the diffusion layer presents a trend of moving to montmorillonite surfaces [10]. When the temperature is below $55^{\circ} \mathrm{C}$, the migration rate of $\mathrm{Na}^{+}$is increased with the temperature improved, which increases the content of $\mathrm{Na}^{+}$on the montmorillonite surface. Therefore, the reaction velocity between $\mathrm{Na}^{+}$and $\mathrm{Ca}^{2+}$ is growing. When the temperature is over $55^{\circ} \mathrm{C}$, part of non ionization water combined with $\mathrm{Ca}^{2+}$ between montmorillonite crystal layers is escaped out because of the high temperature [14], resulting in the increase of migration resistance pressure of interlamination $\mathrm{Ca}^{2+}$, which hinders the ion exchange between $\mathrm{Na}^{+}$and $\mathrm{Ca}^{2+}$ to a certain extent. Above the right temperature, the higher sodium temperature 


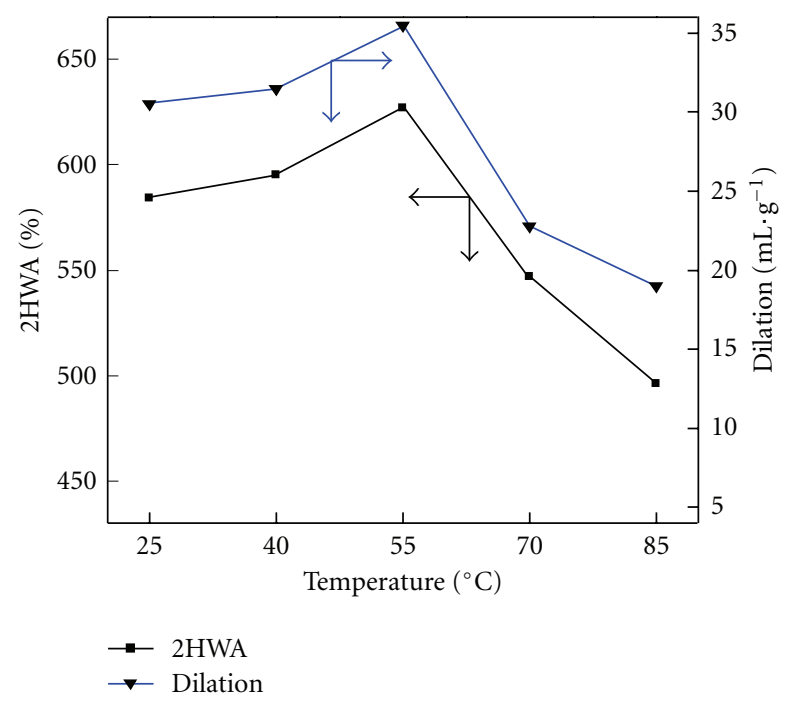

FIGURE 6: Effects of sodium temperature on sodium modification.

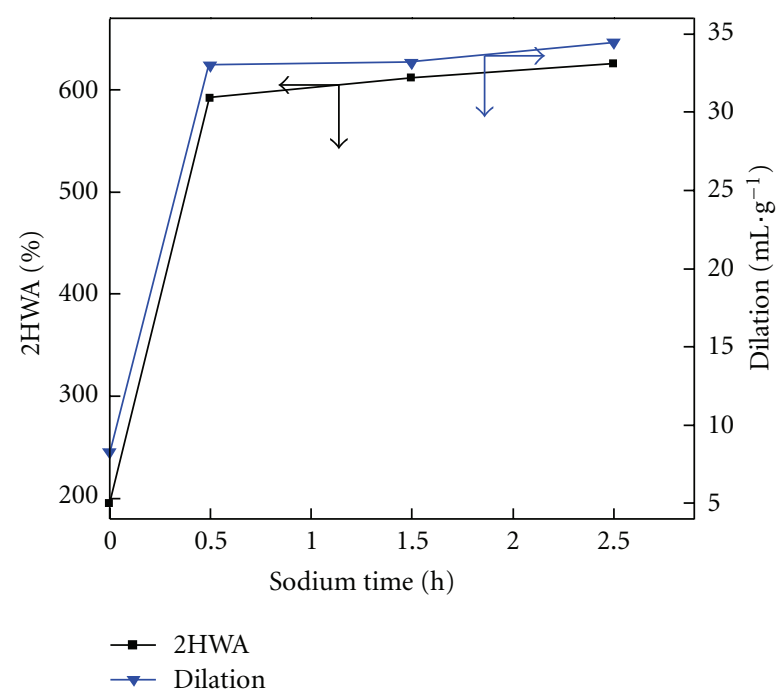

FIGURE 7: Effects of sodium time on the sodium modification.

is, the more interlamination water is out, and the harder $\mathrm{Ca}^{2+}$ is replaced of with $\mathrm{Na}^{+}$.

4.1.4. Sodium Time. Effects of sodium time on sodiummodification are also studied, and the results are shown in Figure 7. The following parameters are fixed: $\mathrm{Na}_{2} \mathrm{CO}_{3}$ dosage of $3.0 \%$, pulp density of $20 \%$, and sodium temperature of $55^{\circ} \mathrm{C}$.

The essence of sodium modification is the ion exchange between $\mathrm{Na}^{+}$and $\mathrm{Ca}^{2+}$. Sodium time will have obvious effects on the sodium reaction balance. It can be seen from Figure 7 that 2HWA and dilation has a sharp increase when the sodium time is less than $0.5 \mathrm{~h}$. With the sodium time increased to $0.5 \mathrm{~h}$, the ion exchange reaction is almost balanced, and the effects of sodium modification nearly reach the optimum. When the time is changed between $0.5 \mathrm{~h}$ and $2.5 \mathrm{~h}, 2 \mathrm{HWA}$ and dilation of modified bentonite are kept

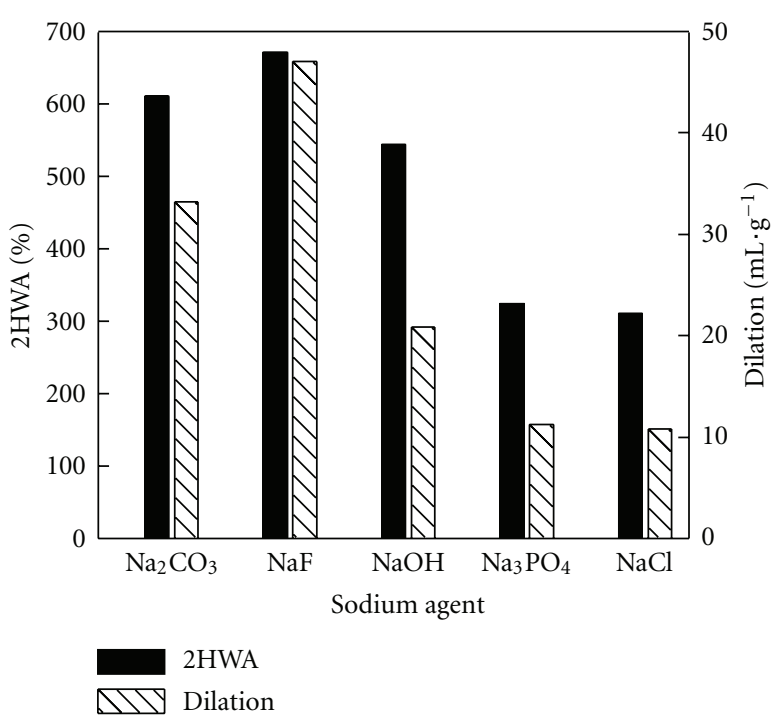

FIGURE 8: Comparison of different sodium agents affecting sodium modification.

TABLE 3: $\mathrm{Na}^{+}$mole number of different sodium agents at the same mass percent.*

\begin{tabular}{lccccc}
\hline Sodium agents & $\mathrm{Na}_{2} \mathrm{CO}_{3}$ & $\mathrm{NaF}$ & $\mathrm{NaOH}$ & $\mathrm{Na}_{3} \mathrm{PO}_{4}$ & $\mathrm{NaCl}$ \\
\hline $\mathrm{Na}^{+}(\mathrm{mol})$ & 0.057 & 0.071 & 0.075 & 0.018 & 0.051 \\
\hline
\end{tabular}
* Note: The sample bentonite is $100 \mathrm{~g}$, and the sodium agent is $3.0 \mathrm{~g}$.

constantly. So in the commercial production, the sodium time is recommended as about $0.5 \mathrm{~h}$.

4.1.5. Comparisons of Different Sodium Agents. Effects of different sodium agents on sodium modification are performed and the results are displayed in Figure 8. The experimental parameters are fixed as follows: sodium agent dosage of $3.0 \%$, pulp density of $20 \%$, sodium temperature of $55^{\circ} \mathrm{C}$, and sodium time of $0.5 \mathrm{~h}$.

At the same mass percent, $\mathrm{Na}^{+}$mole number of different sodium agents has obvious difference, which is listed in Table 3.

From Figure 8, it can be apparently observed that the sodium modification effects of different sodium agents is $\mathrm{NaF}>\mathrm{Na}_{2} \mathrm{CO}_{3}>\mathrm{NaOH}>\mathrm{Na}_{3} \mathrm{PO}_{4}>\mathrm{NaCl}$.

As given in Table $3, \mathrm{Na}^{+}$mole number of $\mathrm{NaF}$ and $\mathrm{NaOH}$ is relatively the most, that of $\mathrm{Na}_{2} \mathrm{CO}_{3}$ and $\mathrm{NaCl}$ is less, and that of $\mathrm{Na}_{3} \mathrm{PO}_{4}$ is the least. When we use $\mathrm{NaF}, \mathrm{NaOH}$, and $\mathrm{Na}_{2} \mathrm{CO}_{3}$ as sodium agents, there are sediments, colloids, or slightly soluble substances formed in the bentonite-water system, which has promoting effects on the sodium reaction. Although $\mathrm{NaCl}$ and $\mathrm{Na}_{2} \mathrm{CO}_{3}$ have the equivalent $\mathrm{Na}^{+}$mole number, $\mathrm{Cl}^{-}$and $\mathrm{Ca}^{2+}$ cannot form colloid or sediments, which is the real reason for the sodium effect of $\mathrm{NaCl}$ worse than that of $\mathrm{Na}_{2} \mathrm{CO}_{3}$. At the same mass percent, $\mathrm{Na}_{3} \mathrm{PO}_{4}$ only provides $0.018 \mathrm{~mol}$ of $\mathrm{Na}^{+}$, far less than the theoretic quantity of $0.066 \mathrm{~mol}$. 
TABLE 4: Main physical properties of the bentonite.

\begin{tabular}{lccc}
\hline & $\begin{array}{c}\text { 2HWA } \\
(\%)\end{array}$ & $\begin{array}{c}\text { Dilation } \\
\left(\mathrm{mL} \cdot \mathrm{g}^{-1}\right)\end{array}$ & $\begin{array}{c}\text { Colloid index } \\
\left(\mathrm{mL} \cdot(3 \mathrm{~g})^{-1}\right)\end{array}$ \\
\hline$(1)$ & 586 & 30.6 & 86.0 \\
$(2)$ & 624 & 35.3 & 89.5 \\
$(3)$ & 593 & 31.3 & 87.4 \\
Average & 601 & 32.4 & 87.6 \\
Ca-bent & 195 & 8.3 & 19.0 \\
Average/Ca-bent & 3.08 & 3.90 & 4.61 \\
\hline
\end{tabular}

TABLE 5: Chemical compositions of the modified bentonite.

\begin{tabular}{lcccccc}
\hline $\mathrm{SiO}_{2}$ & $\mathrm{Al}_{2} \mathrm{O}_{3}$ & $\mathrm{Fe}_{2} \mathrm{O}_{3}$ & $\mathrm{CaO}$ & $\mathrm{MgO}$ & $\mathrm{K}_{2} \mathrm{O}$ & $\mathrm{Na}_{2} \mathrm{O}$ \\
\hline 65.57 & 14.03 & 1.74 & 0.77 & 0.90 & 1.05 & 2.33 \\
\hline
\end{tabular}

As well known, fluorine is a harmful element. So, $\mathrm{Na}_{2} \mathrm{CO}_{3}$ is the best sodium agent for the sodium modification of Ca-Bent.

4.2. Integrated Experiments. From the results mentioned above, the suitable conditions of sodium modification for Hunyuan Ca-Bent are including $\mathrm{Na}_{2} \mathrm{CO}_{3}$ dosage 3.0\%, pulp density $20 \%$, sodium temperature $55^{\circ} \mathrm{C}$ and sodium time $0.5 \mathrm{~h}$.

Repeating the experiment under the optimal conditions for three times, the main physical and chemical properties are measured and given in Tables 4 and 5 .

It can be seen from Table 5 that the content of $\mathrm{Na}_{2} \mathrm{O}$ is obviously increased to $2.33 \%$, by contrast, the content of $\mathrm{CaO}$ is decreased to $0.77 \%$. According to $K=\left(E_{\mathrm{Na}}{ }^{+}+\right.$ $\left.E_{\mathrm{K}}{ }^{+}\right) /\left(E_{\mathrm{Ca}}{ }^{2+}+E_{\mathrm{Mg}}{ }^{2+}\right)$, alkali coefficient $K$ of modified bentonite is calculated as 1.33 (more than 1.0).

Figure 9 presents the XRD patterns of Hunyuan Ca-bent and the modified Na-Bent obtained under the integrated experimental conditions. As shown, $d(001)$ is reduced from $1.5539 \mathrm{~nm}$ down to $1.2467 \mathrm{~nm}, 2 \theta(001)$ is increased from $5.6875^{\circ}$ to $7.0907^{\circ}$. And the peak (001) of curve 1 is cragged and dissymmetry; however, the peak (001) of curve 2 is relatively flat and symmetry. These characteristics apparently indicate that curve 1 is the Ca-Bent XRD pattern, and curve 2 is the Na-Bent XRD pattern.

4.3. Process Flow Recommended. Based on the above results, the sodium-modification process flow is recommended in Figure 10. Suspension method is an effective sodium modification for Ca-Bent. However, the drying of the slurry is the limited section of this method, which is not applied in the Na-Bent commercial production because of the low drying efficiency and long drying time.

In recent years, the spray high-speed centrifugal dryer is developed and successfully used to dry the liquids as emulsion, suspending liquid, colloid, and so on. Compared with traditional drying equipment, the spray high-speed centrifugal dryer possesses high drying speed and thermal

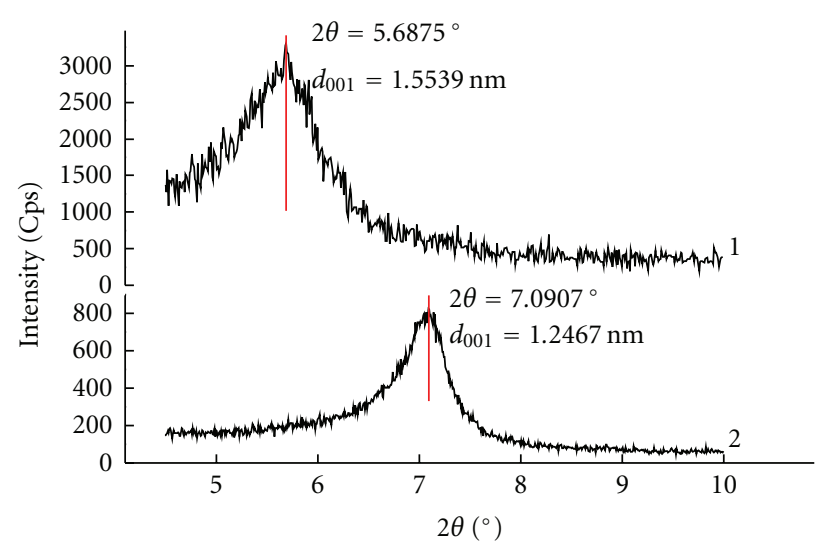

FIGURE 9: XRD patterns of Ca-Bent (curve 1) and modified Na-Bent (curve 2).

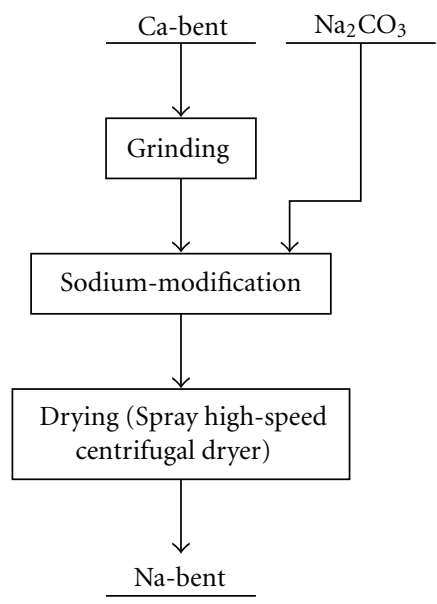

Figure 10: Process flow for sodium modification.

efficiency. Practice shows that the drying time is only $5 \sim$ 15 seconds in general as the drying temperature is about $120 \sim 150^{\circ} \mathrm{C}$. So, it is feasible that this dryer is recommended to dry bentonite.

\section{Conclusions}

(1) Process mineralogy investigations show that Hunyuan bentonite, the reserve of which is more than 0.15 billion tons, is one of large-type typical CaBent deposits in China. The 2HWA, dilation, and colloid index of the Ca-Bent are $195 \%, 8.3 \mathrm{~mL} / \mathrm{g}$, and $19.0 \mathrm{~mL} /(3 \mathrm{~g})$, respectively. Presently, they are not adequately utilized in iron ore pellet production.

(2) By means of suspension method, the alkali coefficient $K$ of modified bentonite is increased from 0.34 to 1.33 , and the $2 \mathrm{HWA}$, dilation, and colloid index are respectively increased to $601 \%, 32.4 \mathrm{~mL} / \mathrm{g}$, and $87.6 \mathrm{~mL} /(3 \mathrm{~g})$, under the optimal conditions of $\mathrm{Na}_{2} \mathrm{CO}_{3}$ dosage $3.0 \%$, pulp density $20 \%$, sodium temperature $55^{\circ} \mathrm{C}$, and sodium time $0.5 \mathrm{~h}$. 
(3) The XRD patterns of bentonite before and after sodium modification show that the $d(001)$ from $1.5539 \mathrm{~nm}$ reduces to $1.2467 \mathrm{~nm}$, and $2 \theta(001)$ from $5.6875^{\circ}$ increases to $7.0907^{\circ}$. It indicated that the Ca-based Hunyuan bentonite changed to $\mathrm{Na}$-Bent successfully.

\section{Acknowledgments}

This research is supported by National Natural Science Foundation of China (No. 50804059), National Science Fund for Distinguished Young Scholars (50725416), and Specialized Research Fund for the Doctoral Program of Higher Education (No. 200805331080).

\section{References}

[1] F. Ju-Ying, J. Tao, and Z. De-Qing, Study on Sintering and Pelletizing, Central South University of Technology Press, Changsha, China, 1996.

[2] S. K. Kawatra and S. J. Ripke, "Developing and understanding the bentonite fiber bonding mechanism," Minerals Engineering, vol. 14, no. 6, pp. 647-659, 2001.

[3] S. K. Kawatra and S. J. Ripke, "Effects of bentonite fiber formation in iron ore pelletization," International Journal of Mineral Processing, vol. 65, no. 3-4, pp. 141-149, 2002.

[4] S. P. E. Forsmo, A. J. Apelqvist, B. M. T. Björkman, and P. O. Samskog, "Binding mechanisms in wet iron ore green pellets with a bentonite binder," Powder Technology, vol. 169, no. 3, pp. 147-158, 2006.

[5] S. K. Kawatra and S. J. Ripke, "Laboratory studies for improving green ball strength in bentonite- bonded magnetite concentrate pellets," International Journal of Mineral Processing, vol. 72, no. 1-4, pp. 429-441, 2003.

[6] L. Peng-Jun, Z. Yu-Zhu, C. Zhao-Zhen, L. Zhen-Guo, and Y. Hai-Sheng, "Preparation of Na-bentonite from Ca-bentonite and its application in pellet," Multipurpose Utilization of Mineral Resources, vol. 4, pp. 3-6, 2006 (Chinese).

[7] J. Gui-Lan and Z. Pei-Ping, The Processing and Application of Bentonite, Chemical Industry Press, Beijing, China, 2005.

[8] J. Chong, Study on Mineralogical Characteristics and Modification of Xiangxi Bentonite, Changsha Research Institute of Mining and Metallurgy, Changsha, China, 2005.

[9] I. Dananaj, J. Frankovská, and I. Janotka, “The influence of smectite content on microstructure and geotechnical properties of calcium and sodium bentonites," Applied Clay Science, vol. 28, no. 1-4, pp. 223-232, 2005.

[10] Z. Jian-Le and C. Wan-Xiong, "Study on enhancing the cationexhange capacity of bentonite by alkali activated," China Non-Metallic Mining Industry Herald, vol. 1, pp. 34-38, 1996 (Chinese).

[11] J. Hong-Min, "Effects of inorganic salt and temperature on the micro-structure of hydrated montmorillonite," Acta Petrolei Sinica, vol. 19, no. 4, pp. 122-127, 1998 (Chinese).

[12] G. J. Churchman, M. Askary, P. Peter, M. Wright, M. D. Raven, and P. G. Self, "Geotechnical properties indicating environmental uses for an unusual Australian bentonite," Applied Clay Science, vol. 20, no. 4-5, pp. 199-209, 2002.

[13] G. R. Alther, "The qualifications of bentonite as a soil sealant," Engineering Geology, vol. 23, no. 3-4, pp. 177-191, 1987.
[14] Y. Xiang-Zhong, "The supervising method of b-axis degree of order for evaluating of active bentonite," Non-Metallic Mines, vol. 5, pp. 5-9, 1993 (Chinese). 



The Scientific World Journal

Submit your manuscripts at

http://www.hindawi.com

\section{World Journal}

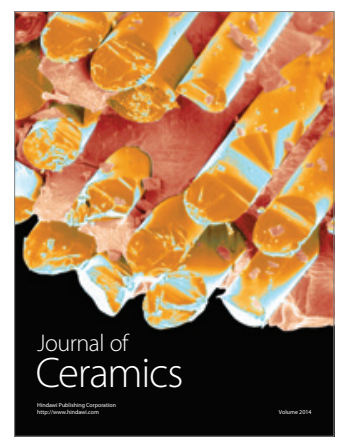

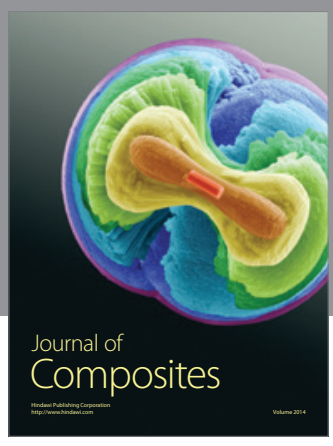
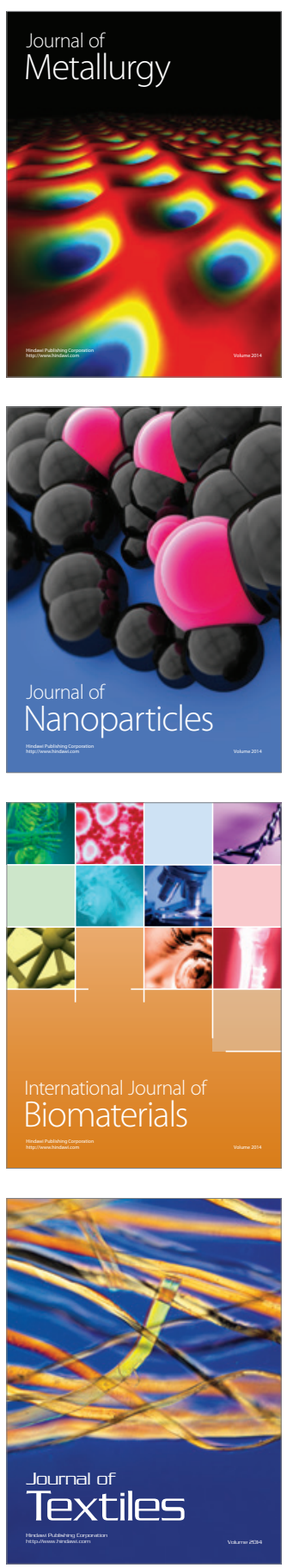